\title{
Quantitative Measurement of IgG to Severe Acute Respiratory Syndrome Coronavirus-2 Proteins Using ImmunoCAP
}

\author{
Behnam Keshavarz $^{a}$ Joesph R. Wiencek ${ }^{b}$ Lisa J. Workman ${ }^{a}$ \\ Matthew D. Straesser ${ }^{a} \quad$ Lyndsey M. Muehling ${ }^{a} \quad$ Glenda Canderan $^{a}$ \\ Fabrizio Drago $^{c}$ Catherine A. Bonham ${ }^{d}$ Jeffrey M. Sturek ${ }^{d}$ Chintan Ramani $^{d}$ \\ Coleen A. McNamara ${ }^{c}$ Judith A. Woodfolk ${ }^{a}$ Alexandra Kadld, e \\ Thomas A.E. Platts-Mills ${ }^{a}$ Jeffrey M. Wilson ${ }^{a}$ \\ aDivision of Allergy \& Clinical Immunology, Department of Medicine, University of Virginia, Charlottesville, VA, USA; \\ ${ }^{\mathrm{b}}$ Department of Pathology, University of Virginia, Charlottesville, VA, USA; 'Division of Cardiovascular Medicine and \\ the Robert M. Berne Cardiovascular Center, University of Virginia, Charlottesville, VA, USA; ${ }^{d}$ Division of Pulmonary \\ and Critical Care, Department of Medicine, University of Virginia, Charlottesville, VA, USA; 'Department of \\ Pharmacology, University of Virginia, Charlottesville, VA, USA
}

\section{Keywords}

Antibody assay $\cdot \lg G \cdot$ COVID-19. Spike receptor-binding

domain · Nucleocapsid

\begin{abstract}
Background: Detailed understanding of the immune response to severe acute respiratory syndrome coronavirus (SARS-CoV)-2, the cause of coronavirus disease 2019 (COVID-19) has been hampered by a lack of quantitative antibody assays. Objective: The objective was to develop a quantitative assay for IgG to SARS-CoV-2 proteins that could be implemented in clinical and research laboratories. Methods: The biotin-streptavidin technique was used to conjugate SARS-CoV-2 spike receptor-binding domain (RBD) or nucleocapsid protein to the solid phase of the ImmunoCAP. Plasma and serum samples from patients hospitalized with
\end{abstract}

Edited by: H.-U. Simon, Bern. karger@karger.com www.karger.com/iaa

Karger $\stackrel{\text { ' }}{=}$

GOPEN ACCESS
(C) 2021 The Author(s)

Published by S. Karger AG, Basel

This is an Open Access article licensed under the Creative Commons Attribution-NonCommercial-4.0 International License (CC BY-NC) (http://www.karger.com/Services/OpenAccessLicense), applicable to the online version of the article only. Usage and distribution for commercial purposes requires written permission.
COVID-19 $(n=60)$ and samples from donors banked before the emergence of COVID-19 $(n=109)$ were used in the assay. SARS-CoV-2 IgG levels were followed longitudinally in a subset of samples and were related to total lgG and IgG to reference antigens using an ImmunoCAP 250 platform. Results: At a cutoff of $2.5 \mu \mathrm{g} / \mathrm{mL}$, the assay demonstrated sensitivity and specificity exceeding $95 \%$ for IgG to both SARS-CoV-2 proteins. Among 36 patients evaluated in a post-hospital follow-up clinic, median levels of IgG to spike-RBD and nucleocapsid were $34.7 \mu \mathrm{g} / \mathrm{mL}$ (IQR 18-52) and $24.5 \mu \mathrm{g} / \mathrm{mL}$ (IQR 9-59), respectively. Among 17 patients with longitudinal samples, there was a wide variation in the magnitude of $\mathrm{lgG}$ responses, but generally the response to spike-RBD and to nucleocapsid occurred in parallel, with peak levels approaching $100 \mu \mathrm{g} / \mathrm{mL}$, or $1 \%$ of total IgG. Conclusions: We have described a quantitative assay to measure IgG to SARS-CoV-2 that could be used in clinical and research laboratories and
Thomas A.E. Platts-Mills

Division of Allergy and Clinical Immunology, University of Virginia PO Box 801355, MR4 Bldg, Lane Rd., Rm 5060

Charlottesville, VA 22908-1355 (USA)

tap2z@virginia.ed

Jeffrey M. Wilson

Division of Allergy and Clinical Immunology, University of Virginia PO Box 801355

Charlottesville, VA 22908-1355 (USA)

jmw2gc@virginia.edu 
implemented at scale. The assay can easily be adapted to measure IgG to mutated COVID-19 proteins, has good performance characteristics, and has a readout in standardized units.

(c) 2021 The Author(s)

Published by S. Karger AG, Basel

\section{Introduction}

Serological assays that quantify antibodies specific for severe acute respiratory syndrome coronavirus (SARSCoV)-2 represent an important tool in the investigation of the epidemiology and immunology of this novel coronavirus, the cause of the coronavirus disease 2019 (COVID-19) pandemic [1-3]. Many studies have reported on antibodies specific for SARS-CoV-2, and however, most of the assays used in these studies have had qualitative and/or semiquantitative readouts and very few have used standardized units (e.g., $\mu \mathrm{g} / \mathrm{mL}$ ) [4-12]. The ImmunoCAP assay developed by Phadia/Thermo Fisher is often considered the gold standard for quantitative detection of IgE antibodies to allergens in both clinical and research laboratories. The platform was designed for IgE detection but can also be used to quantify other antibody isotypes/ subclasses including IgG and IgG4 [13, 14]. The assay has high accuracy, consistency, and reproducibility and has a readout in standardized units (i.e., IU/mL for IgE and $\mu \mathrm{g} /$ $\mathrm{mL}$ for IgG and IgG4) [15]. A major strength of the ImmunoCAP is that antibodies specific for multiple antigenic targets can readily be assessed in parallel. With the emergence of the coronavirus pandemic, we asked whether the ImmunCAP could be used to measure IgG to SARS-CoV-2 proteins. Here, we describe a novel assay that takes advantage of the biotin-streptavidin technique to link commercially available recombinant SARS-CoV-2 proteins to the high-capacity absorbent solid phase of the ImmunoCAP $[16,17]$. The assay was developed using plasma and serum samples from established COVID-19 patients and also samples from control subjects banked prior to the pandemic. Our results suggest that the ImmunoCAP-based approach has good performance characteristics and offers several advantages over many commercial assays currently in use.

\section{Materials and Methods}

\section{Reagents}

Recombinant SARS-CoV-2 S1 receptor-binding domain (RBD) subunit and recombinant SARS-CoV-2 nucleocapsid protein which had been expressed in HEK293 cells were purchased from RayBiotech (Peachtree Corners, GA, USA). Human coronavirus (HCoV-229E) spike protein (S1 subunit, His Tag) and human coronavirus (HCoV-OC43) spike protein (S1 subunit, His Tag) were purchased from Sino Biological (Wayne, PA, USA). The recombinant monoclonal anti-SARS-CoV-2 spike glycoprotein S1 antibody (CR3022) was purchased from Abcam (Cambridge, MA, USA). Streptavidin ImmunoCAPs and tetanus toxoid ImmunoCAPs, as well as ImmunoCAPs to measure total IgG, were purchased from Thermo Fisher Scientific (Portage, MI, USA). Galactose- $\alpha$-1,3-galactose- $\beta-1,4$-GlcNAc-HSA (3 atom spacer) was purchased from Dextra (Reading, UK).

\section{Coronavirus Disease-19 Patients and Controls}

Samples were available from 60 confirmed COVID-19 cases. De-identified plasma samples from 15 patients hospitalized with COVID-19 were available through the clinical laboratory for initial assay development carried out under the common rule. Paired serum and plasma samples were available from 36 patients with $\mathrm{CO}$ VID-19 seen in outpatient post-hospitalization follow-up clinic as part of a University of Virginia (UVA) Institutional Review Board (IRB) approved investigation (HSR\#200148). Serum samples were available from 17 patients at various longitudinal time points during inpatient admission for management of COVID-19 as part of a UVA IRB-approved investigation (HSR\#200171), 8 of which were also seen in the outpatient follow-up clinic. Inpatient samples were collected at days 0,1 , and 7 of hospitalization. For this longitudinal cohort, the day at which the sample was collected was normalized in relation to initial symptom onset (and expressed as days after symptom onset). Serum from allergic and nonallergic adults ( $n=109)$ obtained prior to December 2019 as part of a UVA IRBapproved investigation (\#13298) were used as reference controls. All patients/participants in the IRB-approved studies provided written informed consent.

\section{IgG ImmunoCAP Assays}

The biotin-streptavidin technique was used to link target antigens to the solid phase of the ImmunoCAP assay. Biotinylation was performed using EZ-Link Sulfo-NHS-LC-Biotin (ThermoScientific, Waltham, MA, USA). Briefly, to $500 \mu \mathrm{L}$ of $2 \mathrm{mg} / \mathrm{mL}$ protein solution, $60 \mu \mathrm{L}$ of $2 \mathrm{mg} / \mathrm{mL}$ of biotin was added. Mixtures were placed in the dark and incubated for $4 \mathrm{~h}$ at room temperature. The biotinylated proteins were dialyzed against $\mathrm{PBS}$ at $4^{\circ} \mathrm{C}$ for $24 \mathrm{~h}$ with 3 buffer changes. In initial optimization experiments, different amounts of biotinylated spike-RBD and nucleocapsid proteins were conjugated to the solid phase $(4,2,1,0.5$, and $0.25 \mu \mathrm{g})$. Subsequent experiments used $1.25 \mu \mathrm{g}$ of SARS-CoV-2 protein to prepare each ImmunoCAP. For the $\alpha$-Gal assay, $2 \mu \mathrm{g}$ of biotinylated $\alpha$-Gal-HSA was used to prepare each ImmunoCAP. Total IgG was measured according to manufacturer's instructions using a 1:200 benchtop dilution. Assays were carried out with an ImmunoCAP 250 (Thermo Fisher Scientific), using an internal calibrator curve ranging from 2 to $200 \mu \mathrm{g} / \mathrm{mL}$ that is provided by the manufacturer. The accuracy of this calibrator, which is not antigen-specific, was confirmed by assaying known concentrations of the anti-SARSCoV-2 spike glycoprotein S1 antibody (CR3022) using spike-RBD ImmunoCAPs.

\section{Statistical Analysis}

Antibody levels were non-normally distributed and were compared by Mann-Whitney U test. The cutoff threshold of the assay 


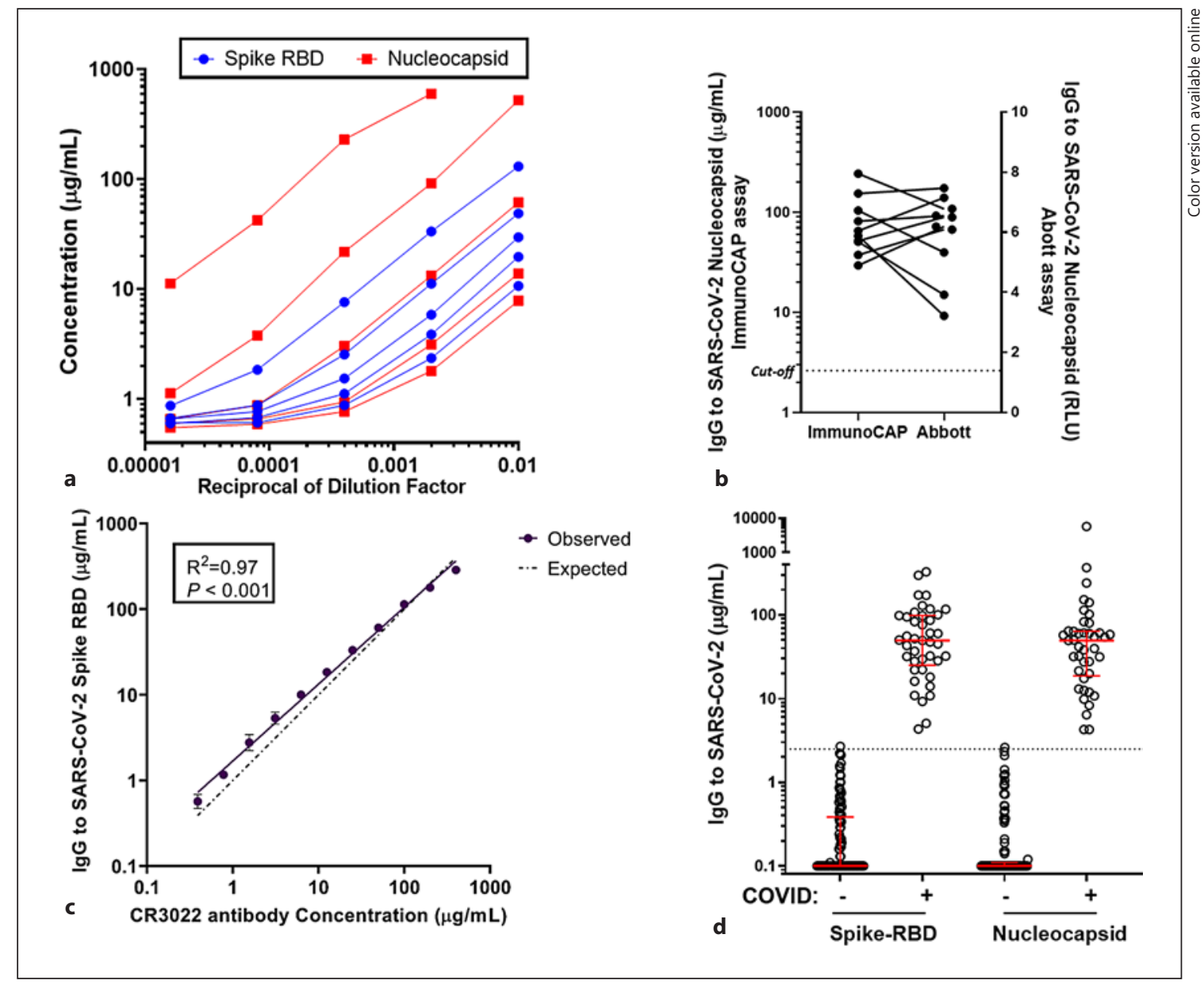

Fig. 1. a Dilution curves for IgG to SARS-CoV-2 spike-RBD and nucleocapsid (5-fold dilutions, $n=5$ ). b Comparison of results of IgG to SARS-CoV-2 nucleocapsid using ImmunoCAP and Abbott assay $(n=10)$. c Concentration response curve using the anti-spike glycoprotein S1 monoclonal antibody CR3022 (2-fold dilutions carried out in triplicate \pm SD). $\mathbf{d}$ IgG to SARS-CoV-2 spike-RBD and nucleocapsid in COVID-19 patients $(n=51)$ and controls $(n=109)$. SARS-CoV-2, severe acute respiratory syndrome coronavirus-2; COVID-19, coronavirus disease 2019; RBD, receptor-binding domain.

as well as sensitivity and specificity of the assay for spike-RBD and nucleocapsid was determined using receiver operating characteristic curve analysis. Correlation between concentration of the monoclonal antibody CR3022 and assay readout were determined using simple linear regression. All analyses were performed using GraphPad Prism V8.4 (San Diego, CA, USA).

\section{Results}

\section{Assay Development}

The assay was initially developed using plasma from 15 de-identified patients hospitalized with COVID-19 who had been confirmed to have IgG to SARS-CoV-2 with the FDA-EUA-approved Abbott Architect i2000 immunoassay. To measure IgG antibody to SARS-CoV-2, streptavidin-linked immunosorbents were prepared using $1.25 \mu \mathrm{g}$ of biotinylated spike-RBD or nucleocapsid protein, as determined in preliminary optimization experiments (see online suppl. Fig. 1; for all online suppl. material, see www.karger.com/doi/10.1159/000514203). Dilution curves carried out at 1:100, 1:500, 1:2,500, $1: 12,500$, and 1:62,500 (accounting for the 1:100 onboard dilution) exhibited parallelism for both SARS-CoV-2 proteins (Fig. 1a). Observed values with the nucleocapsid ImmunoCAP assay generally aligned with the results of the Abbott assay, which used nucleocapsid on the solid 


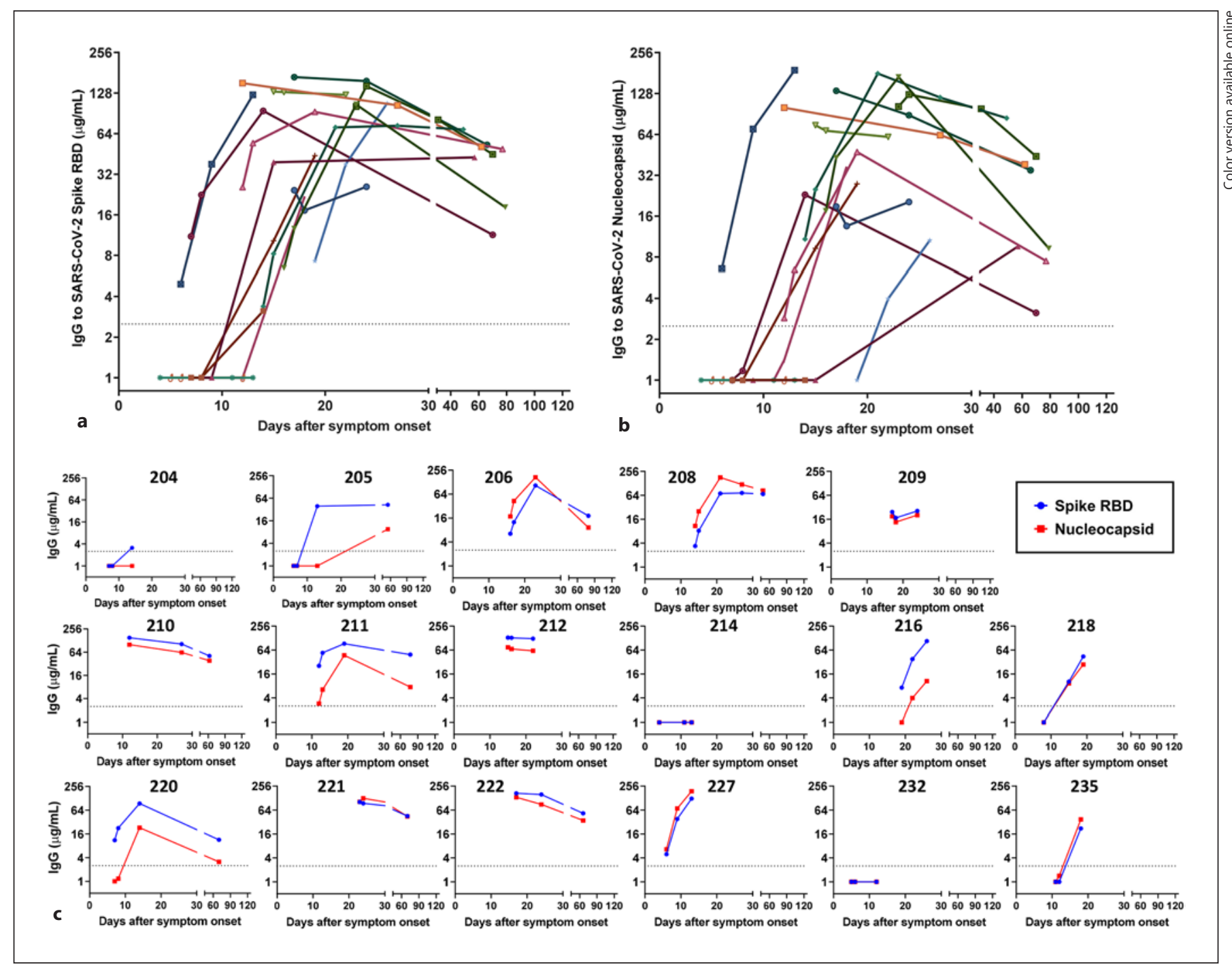

Fig. 2. Longitudinal sampling of IgG to SARS-CoV-2 spike-RBD (a) and nucleocapsid with ImmunoCAP (b) in 17 patients hospitalized with COVID-19. c IgG to spike-RBD and nucleocapsid in individual patients. All samples after day 40 were obtained from a post-hospital follow-up clinic. SARS-CoV-2, severe acute respiratory syndrome coronavirus-2; COVID-19, coronavirus disease 2019; RBD, receptor-binding domain.

phase, in a head-to-head comparison (Fig. 1b). Initial results using matched plasma and serum from seroconverted patients showed negligible differences, demonstrating both types of specimens can be used in this assay (online suppl. Fig. 2). To confirm the quantitative accuracy of the assay, we utilized a monoclonal anti-SARS-CoV-2 spike S1 IgG1 antibody (CR3022) [5]. The concentration of CR3022 mAb [5] used in the assay correlated closely with the assay readout $\left(R^{2}=0.97, p<0.001\right)$ (Fig. 1c).

To determine an optimal cutoff limit and nonspecific binding in the assay, samples from COVID-19 patients $(n=51)$ and samples from allergic and nonallergic donors banked prior to the emergence of COVID-19 $(n=109)$ were assayed using ImmunoCAPs conjugated with SARSCoV-2 protein and also unconjugated "naked" streptavidin ImmunoCAPs. The COVID-19 samples were obtained from the 15 hospitalized patients described above, as well as 36 patients evaluated in an outpatient follow-up clinic following hospitalization for COVID-19 [18]. IgG binding to naked streptavidin ImmunoCAPs was observed at low levels in both COVID-19 and pre-COVID-19 samples (online suppl. Fig. 3). To account for this 
background binding, the result obtained with the streptavidin ImmunoCAP was henceforth subtracted from the result obtained using viral antigen for each sample that was assayed. At a cutoff threshold of $2.5 \mu \mathrm{g} / \mathrm{mL}$, the assay had $100 \%$ sensitivity and $99 \%$ specificity in receiver operating characteristic curve analysis for both the spike-RBD and nucleocapsid assay (Fig. 1d). Of note, this value is only marginally different from the value of $2 \mu \mathrm{g} / \mathrm{mL}$, which is the lower end of the assay's measuring range according to the manufacturer's instructions and within the range in which the assay exhibited parallelism in dilution experiments (Fig. 1a).

\section{Application of the Assay in Coronavirus Disease-19}

Cases Followed Longitudinally

Next, we used the assay to measure IgG antibodies to SARS-CoV-2 proteins in 17 patients hospitalized with a primary diagnosis of COVID-19 in which longitudinal blood draws were available. None of these patients had received convalescent plasma and the majority had severe disease as reflected by admission to the intensive care unit and a requirement of mechanical ventilation (online suppl. Table 1). Among these patients, the seroconversion rate was $88 \%$ for spike-RBD (15 of 17 patients) and $83 \%$ for nucleocapsid (14 of 17 patients), considering the whole duration of the study (Fig. 2a, b). Of note, none of the patients who failed to seroconvert had samples available at time points later than 14 days post-symptom onset. IgG to both spike-RBD and nucleocapsid proteins generally occurred in parallel, were positive within 10-12 days after the onset of symptoms and decreased over time (Fig. 2c).

\section{Levels of IgG to Severe Acute Respiratory Syndrome}

Coronavirus-2 in Relation to Non-Severe Acute

Respiratory Syndrome Coronaviruses and Reference

Antigens

We next sought to determine how levels of IgG to SARS-CoV-2 (spike-RBD) in the subacute (defined as day 14-28 post-symptom onset) and convalescent (posthospitalization, median $=70$ days post-symptom onset) phase compared to baseline levels of IgG to the spike S1 protein of 2 non-SARS coronaviruses (HCoV). We focused on $\mathrm{HCoV}-229 \mathrm{E}$ and $\mathrm{HCoV}-\mathrm{OC} 43$ as these 2 coronaviruses represent important causes of community upper respiratory viral infections [19]. We also assessed 2 reference antigens that were expected to be recognized by high levels of IgG. Tetanus toxoid represents an antigen to which most individuals are routinely immunized and galactose- $\alpha$-1,3-galactose ( $\alpha-\mathrm{Gal})$ is an oligosaccharide of

Quantitative Measurement of IgG to SARS-CoV-2 nonprimate mammals which is the target of abundant IgG in immunocompetent humans [20]. The results revealed that levels of IgG to SARS-CoV-2 in patients with severe COVID (in the subacute and convalescent phase) were higher than levels of IgG specific for $\mathrm{HCoV}-\mathrm{OC} 43$ and $\mathrm{HCoV}-229 \mathrm{E}$, and also tetanus toxoid or $\alpha-\mathrm{Gal}$ (MannWhitney, $p<0.01$ for each comparison) (Fig. 3a). Total IgG levels trended higher in the COVID-19 patients, but this did not achieve significance (Mann-Whitney, $p=$ 0.16). Responses to SARS-CoV-2 in the subacute phase represented nearly $1 \%$ of total IgG (Fig. 3b). Interestingly, IgG to $\alpha$-Gal represented $<0.1 \%$ of total IgG in both cases and controls, a level lower than previously reported [20]. Finally, this analysis allowed us to explore the effects of preexisting immunity to $\mathrm{HCoV}$ on the magnitude of IgG to SARS-CoV-2 that developed in COVID-19 patients. Baseline levels of IgG to HCoV-229E and HCoV-OC43 spike S1 were paired with the highest value for IgG to SARS-CoV-2 that was observed in the subacute phase. Samples with the lowest levels of IgG to HCoV-229E and $\mathrm{HCoV}-\mathrm{OC} 43$ appeared to have relatively higher levels of IgG to SARS-CoV-2, though this analysis was limited by sample size considerations (Fig. 3c).

\section{Discussion/Conclusion}

The majority of serologic studies of COVID-19, and also commercial assays for measuring IgG to SARS$\mathrm{CoV}-2$, have been limited by a lack of quantitative information about antiviral antibodies in standardized units. Here, we have shown that the ImmunoCAP assay, which is well known for its strong performance characteristics for IgE measurement and is used in clinical and research labs across the globe, can be readily adapted for the quantitative measurement of IgG to SARS-CoV-2 proteins. In the current study, the assay has high sensitivity and specificity and, unlike the majority of commercial assays, has a readout in standardized units $(\mu \mathrm{g} / \mathrm{mL})$. A particular strength of the approach is that up to 20 separate assays, including assays that use novel antigens that have been linked to the solid phase by the biotin-streptavidin technique, can be run in parallel using a single $20 \mu \mathrm{L}$ sample. Applying the assay, we have shown that peak levels of IgG to SARS-CoV-2 spike-RBD and nucleocapsid can approach or exceed $100 \mu \mathrm{g} / \mathrm{mL}$, equivalent to $\sim 1 \%$ of total IgG, in the subacute phase of infection before waning over time. This level significantly exceeded steady-state levels that were detected to major representative antigens, that is, IgG to tetanus toxoid, $\alpha-\mathrm{Gal}$, and also to $\mathrm{HCoV}$.

Int Arch Allergy Immunol 2021;182:417-424 


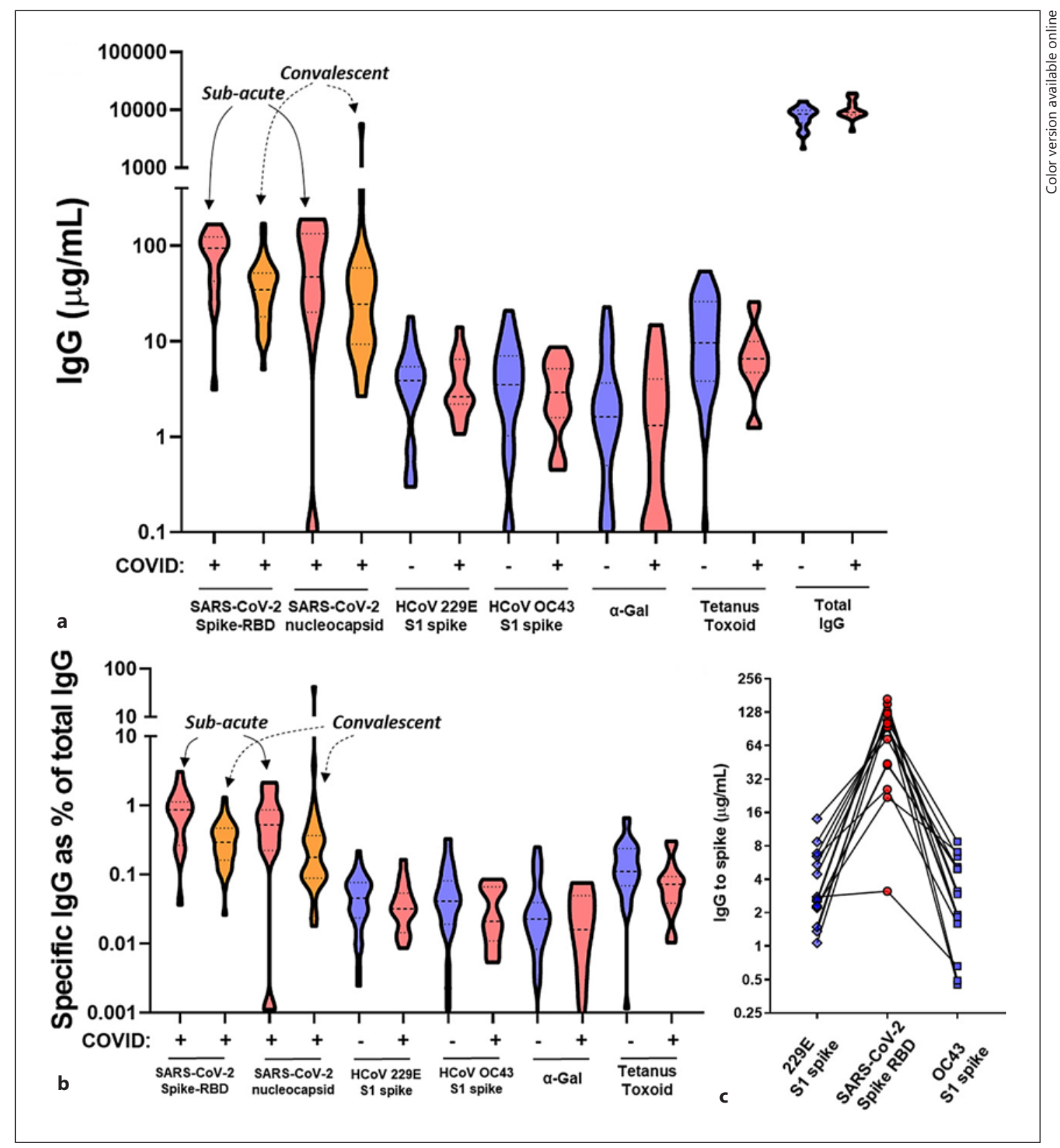

Fig. 3. a Levels of IgG to SARS-CoV-2 spike-RBD, non-SARS coronaviruses and reference antigens with ImmunoCAP, and also total IgG, among controls $(n=29)$ and COVID-19 patients sampled in the subacute $(n=15$, denoted in red) or convalescent ( $n=36$, denoted in orange) phase. $\mathbf{b}$ IgG levels expressed in relation to total IgG. c Relationship between IgG to SARS-CoV-2 at the subacute time point and IgG to non-SARS HCoV. SARS$\mathrm{CoV}-2$, severe acute respiratory syndrome coronavirus-2; COVID-19, coronavirus disease 2019; RBD, receptorbinding domain.

The timing and trajectory of anti-SARS-CoV-2 IgG in our assay generally fit with prior reports, with levels peaking within 3 weeks of symptom onset and showing a significant decrease within 3 months $[5,8,21,22]$. Although preliminary, our data also suggest that preexisting immu- nity to $\mathrm{HCoV}$ could affect the development of IgG to SARS-CoV-2.

The current investigation of COVID-19 cases primarily included serum/plasma samples from those cases that were severe, as reflected by intensive care admission status 
and mechanical ventilation history. We acknowledge that the performance characteristics of the assay may differ when studying mild or asymptomatic COVID-19 cases. To date, we have not compared the results from ImmunoCAP with results of neutralizing antibody assay. This is an important next step, however, other groups have convincingly reported that IgG to spike-RBD correlates with results using neutralization assays $[23,24]$. Our data also suggests that nonspecific binding (background) in this system is $\sim 1-3 \mu \mathrm{g} / \mathrm{mL}$. This may be higher than background values observed in other assay systems; however, we have addressed this by accounting for binding to unconjugated streptavidin ImmunoCAPs for each sample. Acknowledging these limitations, the assay we have described has several strengths compared to many of the serological approaches currently being used in COVID-19 research and patient care. The ImmunoCAP-based assay we have described can readily be adapted to study IgG to SARS-CoV-2 and also many other antigens by using commercially available ImmunoCAPs or the streptavidin-biotin technique. The assay has good performance characteristics, has a quantitative readout in standardized units, and could be used by laboratories across the globe that routinely uses the ImmunoCAP [25].

\section{Acknowledgements}

The authors thank William Petri, Pat Pramoonjago, Deborah Murphy, and colleagues affiliated with the UVA COVID-19 Biorepository and clinical research teams; Jonas Lidholm at Thermo Fisher Scientific for helpful conversations about ImmunoCAP assay development; and Christopher Moskaluk and Lindsay Bazydlo for facilitating access to samples from the clinical laboratory. Current address of Joesph R. Wiencek is Department of Pathology, Immunology, and Microbiology, Vanderbilt University School of Medicine, Nashville, TN.

\section{Statement of Ethics}

A preprint version of the manuscript is available at medRxiv, DOI: https://doi.org/10.1101/2020.11.09.20228411. This study was approved by the IRB for Health Sciences Research at the UVA. All patients/participants in the IRB-approved studies provided written informed consent.

\section{Conflict of Interest Statement}

T.P.M. has a patent on an IgE assay to $\alpha-G a l$ and has received assay support from Thermo Fisher Scientific. J.W. has received consultant fees and assay support from Thermo Fisher Scientific. The other authors have no conflicts of interest to declare.

\section{Funding Sources}

NIH T32 AI007496 (L.M.), NIH K23HL143135 (C.B.), UL1TR003015 and KL2TR003016 (J.S.), NIH R37 AI20565 (T.P.M.), UVA Manning COVID-19 Research Fund, and AAAAI Faculty Development Award (J.W.) provide support for this study.

\section{Author Contributions}

B.K. contributed to the study design, acquisition, analysis, and writing of the paper. L.J.W. and M.D.S. contributed to the study design and sample acquisition and critically reviewed the manuscript. J.R.W., L.M.M., G.C., F.D., C.A.B., J.M.S., C.R., C.A.M., J.A.W., and A.K. contributed to sample acquisition and critically reviewed the manuscript. T.A.E.P.-M. and J.M.W. contributed to the study design, analysis, interpretation, and writing of the paper. All authors have read and approved the final version of this paper.

\section{References}

1 Dong E, Du H, Gardner L. An interactive web-based dashboard to track COVID-19 in real time. Lancet Infect Dis. 2020 May;20(5): 533-4.

2 Zhou P, Yang XL, Wang XG, Hu B, Zhang L, Zhang $\mathrm{W}$, et al. A pneumonia outbreak associated with a new coronavirus of probable bat origin. Nature. 2020 Mar;579(7798):270-3.

3 Zhu N, Zhang D, Wang W, Li X, Yang B, Song $\mathrm{J}$, et al. A Novel coronavirus from patients with pneumonia in China, 2019. N Engl J Med. 2020 Feb 20;382(8):727-33.
4 Amanat F, Stadlbauer D, Strohmeier S, Nguyen THO, Chromikova V, McMahon M, et al. A serological assay to detect SARS-CoV-2 seroconversion in humans. Nat Med. $2020 \mathrm{Jul}$; 26(7):1033-6.

5 Ibarrondo FJ, Fulcher JA, Goodman-Meza D, Elliott J, Hofmann C, Hausner MA, et al. Rapid decay of Anti-SARS-CoV-2 antibodies in persons with mild covid-19. N Engl J Med. 2020 Sep 10;383(11):1085-7.

6 Jackson LA, Anderson EJ, Rouphael NG, Roberts PC, Makhene M, Coler RN, et al. An mRNA vaccine against SARS-CoV-2: preliminary report. N Engl J Med. 2020 Nov 12; 383(20):1920-31.
7 Merrill AE, Jackson JB, Ehlers A, Voss D, Krasowski MD. Head-to-head comparison of two SARS-CoV-2 serology assays. J Appl Lab Med. 2020 Nov 1;5(6):1351-7.

8 Patel MM, Thornburg NJ, Stubblefield WB, Talbot HK, Coughlin MM, Feldstein LR, et al. Change in antibodies to SARS-CoV-2 over 60 days among health care personnel in Nashville, Tennessee. JAMA. 2020 Sep 17;324(17): 1781-2.

9 Robbiani DF, Gaebler C, Muecksch F, Lorenzi JCC, Wang Z, Cho A, et al. Convergent antibody responses to SARS-CoV-2 in convalescent individuals. Nature. 2020 Aug;584(7821): 437-42. 
10 Schnurra C, Reiners N, Biemann R, Kaiser T, Trawinski H, Jassoy C. Comparison of the diagnostic sensitivity of SARS-CoV-2 nucleoprotein and glycoprotein-based antibody tests. J Clin Virol. 2020 Aug; 129: 104544.

11 Shen C, Wang Z, Zhao F, Yang Y, Li J, Yuan J, et al. Treatment of 5 critically Ill patients with COVID-19 with convalescent plasma. JAMA. 2020 Apr 28;323(16):1582-9.

12 Weidner L, Gänsdorfer S, Unterweger S, Weseslindtner L, Drexler C, Farcet M, et al. Quantification of SARS-CoV-2 antibodies with eight commercially available immunoassays. J Clin Virol. 2020 Aug;129:104540.

13 Chapman MD, Wuenschmann S, King E, Pomés A. Technological innovations for highthroughput approaches to in vitro allergy diagnosis. Curr Allergy Asthma Rep. 2015 Jul; 15(7):36.

14 Schuyler AJ, Wilson JM, Tripathi A, Commins SP, Ogbogu PU, Kruzsewski PG, et al. Specific IgG4 antibodies to cow's milk proteins in pediatric patients with eosinophilic esophagitis. J Allergy Clin Immunol. 2018 Jul; 142(1):139-48.e12.
15 van Hage M, Hamsten C, Valenta R. ImmunoCAP assays: pros and cons in allergology. J Allergy Clin Immunol. 2017 Oct;140(4):974-

16 Erwin EA, Custis NJ, Satinover SM, Perzanowski MS, Woodfolk JA, Crane J, et al. Quantitative measurement of IgE antibodies to purified allergens using streptavidin linked to a high-capacity solid phase. J Allergy Clin Immunol. 2005 May;115(5):1029-35.

17 Chung CH, Mirakhur B, Chan E, Le QT, Berlin J, Morse M, et al. Cetuximab-induced anaphylaxis and IgE specific for galactose-alpha-1,3-galactose. N Engl J Med. 2008 Mar 13;358(11):1109-17.

18 Ramani C, Davis EM, Kim JS, Provencio JJ, Enfield KB, Kadl A. Post-intensive care unit COVID-19 outcomes: a case series. Chest. 2021 Jan;159(1):215-8.

19 Sariol A, Perlman S. Lessons for COVID-19 immunity from other coronavirus infections. Immunity. 2020 Aug 18;53(2):248-63.

20 Galili U. Anti-Gal: an abundant human natural antibody of multiple pathogeneses and clinical benefits. Immunology. 2013;140(1): $1-11$.
21 Long QX, Tang XJ, Shi QL, Li Q, Deng HJ, Yuan J, et al. Clinical and immunological assessment of asymptomatic SARS-CoV-2 infections. Nat Med. 2020 Aug;26(8):1200-4.

22 To KK, Tsang OT, Leung WS, Tam AR, Wu TC, Lung DC, et al. Temporal profiles of viral load in posterior oropharyngeal saliva samples and serum antibody responses during infection by SARS-CoV-2: an observational cohort study. Lancet Infect Dis. 2020 May;20(5): 565-74.

23 Cao Y, Su B, Guo X, Sun W, Deng Y, Bao L, et al. Potent neutralizing antibodies against SARS-CoV-2 identified by high-throughput single-cell sequencing of convalescent patients' B cells. Cell. 2020 Jul 9;182(1):73-84. e16.

24 Liu L, Wang P, Nair MS, Yu J, Rapp M, Wang $\mathrm{Q}$, et al. Potent neutralizing antibodies against multiple epitopes on SARS-CoV-2 spike. Nature. 2020 Aug;584(7821):450-6.

25 Keshavarz B, Wiencek JR, Workman LJ, Straesser MD, Muehling LM, Canderan G, et al. Quantitative measurement of IgG to SARS-CoV-2 proteins using ImmunoCAP. medRxiv. 2020 Nov 12 [Preprint]. Available from: https://doi.org/10.1101/2020.11.09.202 28411. 